\title{
Analysis on Muscle Activities in the Upper Body of Caregivers according to Drive-Assisting Speeds of a Shower Carrier
}

\author{
Cheol Woong Ko ${ }^{1}$, Deok Yeon $\mathrm{Cho}^{2}$, Tae Soo $\mathrm{Bae}^{3}$ \\ ${ }^{1}$ Smart Welfare Technology R\&D Group, Korea Institute of Industrial Technology (KITECH), Cheonan, 331-825 \\ ${ }^{2}$ Research Coordination Team, Hyundai Sungwoo Automotive Co., Ltd., Seongnam, 463-820 \\ ${ }^{3}$ Department of Biomedical Engineering, Jungwon University, Geosan, 367-805
}

\begin{abstract}
Objective: The objective of this study was to investigate the effects of drive-assisting system in a shower carrier on the upper body muscle activities of caregivers through drivability tests. Background: In care facilities, one of the major ADL (Activities of Daily Living) factors is bathing/showering. Recently, bath/shower-assisting equipment is actively being introduced in care facilities to reduce caregivers' muscle burden. In particular, it is desirable to utilize a shower carrier equipped with drive-assisting system to effectively care for the elderly. However, there were few systematic studies on the relationship between muscle activities and drive-assisting speeds. Method: For the drivability tests to study the effects on the muscle activities according to the drive-assisting speeds(corresponding drive-voltages: $0.0 \mathrm{~V}, 2.0 \mathrm{~V}, 2.1 \mathrm{~V}, 2.3 \mathrm{~V}$ ), 6 females in their $40 \mathrm{~s}(43 \pm 4 \mathrm{yrs}, 157 \pm 5 \mathrm{~cm}$, and $54.5 \pm 1.5 \mathrm{~kg})$ were selected. To measure muscle activities of caregivers through drivability tests, 7 muscles in the upper body(TM/Trapezius Muscle, DM/Deltoid Muscle, BBM/Biceps Brachii Muscle, TBM/Triceps Brachii Muscle, ECRLM/Extensor Carpi Radialis Longus Muscle, FCUM/Flexor Carpi Ulnaris Muscle, and ESM/Erector Spinae Muscle) were selected. Results: In the TM, muscle activities were decreased as $21 \%$ compared to $0.0 \mathrm{~V}$, when drive-voltage $2.0 \mathrm{~V}$ was applied, as $57 \%$ by $2.1 \mathrm{~V}$, and $62 \%$ by $2.3 \mathrm{~V}(p<0.05)$, whereas $40 \%, 56 \%$, and $69 \%$ of muscles activities were decreased respectively from the $\operatorname{DM}(p<0.05)$. Also, from the UL(BBM+TBM+ECRLM+FCUM), muscle activities were decreased by $17 \%$ with $2.0 \mathrm{~V}$ as against $0.0 \mathrm{~V}$, by $47 \%$ with $2.1 \mathrm{~V}$, and $52 \%$ with $2.3 \mathrm{~V}$, whereas decreases in muscle activities from the ESM were found by $20 \%, 34 \%$, and $42 \%$ respectively by $2.0 \mathrm{~V}, 2.1 \mathrm{~V}$, and $2.3 \mathrm{~V}(p<0.05)$. Conclusion: The muscle activities were decreased in the order of the DM, TM, ESM, and UL. As muscle activities were remarkably reduced as drive voltage were increased, it was expected to reduce the upper body muscle burden on the caregivers when using shower carriers equipped with driving-assist system. Applications: The results from this study can be applied for the development of a shower carrier including other equipment to possibly reduce the muscle burden of the caregivers.
\end{abstract}

Keywords: Aging, Shower carrier, Caregiver, Muscle burden, Drive-assisting system

Corresponding Author: Cheol Woong Ko. Smart Welfare Technology R\&D Group, Korea Institute of Industrial Technology (KITECH), Cheonan, 331-825. Mobile: +82-10-2968-1107, E-mail: chekokitech.re.kr Copyright@2013 by Ergonomics Society of Korea(pISSN:1229-1684 eISSN:2093-8462). All right reserved.

(c) This is an open-access article distributed under the terms of the Creative Commons Attribution Non-Commercial License(http://creativecommons.org/licenses/by-nc/3.0/), which permits unrestricted non-commercial use, distribution, and reproduction in any medium, provided the original work is properly cited. http://www.esk.or.kr 


\section{Introduction}

최근 생활수준의 향상 및 의료기술의 발전으로 평균수명 이 크게 연장되고 있다. 이에 따른 고령화 문제는 국가적 . 사회적으로 심각한 관심사로 부각되고 있으며, 고령자의 생 활수준 개선 및 향상을 위한 복지정책의 구현이 강하게 요 구되고 있다. 특히, 장기요양기관과 같은 고령자 관련 사회 복지 시설은 전국적으로 증가하고 있는 추세이며(National Statistical Office, 2011), 거동이 불편한 고령자의 일상생활 개호활동(Care Service)을 위한 수발자(Caregiver)의 역할 도 더욱 중요시 되고 있다.

일반적으로 요양기관에서의 고령자에 대한 일상생활 수 행능력 (ADL, Activities of Daily Living) 의 주요 4대 요소 는 식사, 배변, 이송/이동, 그리고 목욕/샤워행위로 구분된다 (Korean Gerontological Society, 2002). 특히, 인간의 삶 의 질 관점에서 볼 때, 목욕/샤워행위는 청결유지, 질병치료 및 억제, 2 차 질병예방 등의 효과가 있으며, 질병이나 장애와 무관하게 지속적으로 요구되는 필수활동이다. 하지만, 거동 이 불편한 고령자는 독립적인 목욕/샤워행위가 원활하지 못 하기 때문에 1 인 이상의 수발자의 도움이 필요하며, 이로 인 하여 수발자에게는 많은 근력부담이 요구된다. 특히, 요양시 설에서는 40 50대 여성 수발자가 주로 고령자 개호활동을 담당하고 있기 때문에, 여성 수발자의 근력부담 경감을 위하 여 다양한 목욕/샤워 보조장비의 적극적인 도입이 시급한 실 정이다(Cho et al., 2012).

샤워캐리어는 거동이 불편한 고령자의 샤워 수발을 위 한 대표적인 보조장비 중의 하나로, 주로 고령자 이송행위 (Transferring/Lifting), 실내 이동행위 (Moving), 욕실 내 샤워행위 (Showering)에 이용되고 있다(Figure 1). 일반적 으로 이송행위와 샤워행위는 각각의 보조기기(이송기기, 샤 워보조기기)를 고정한 상태 즉 정지상태에서만 사용함으로 수발자의 근력부담이 크지 않다. 하지만, 실내 이동행위의 경우 주행보조기기(Carrier)를 이용하여 고령자/환자를 개 호시설 내에서 자유롭게 왕래하고자 할 때 사용되므로 상대
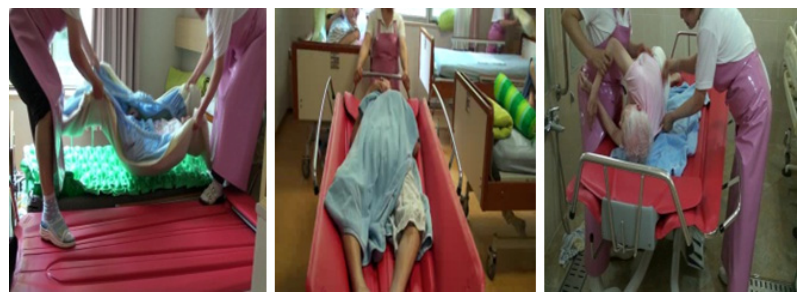

Figure 1. Three major care activities of caregivers using shower carrier in long-term care institution
적으로 수발자의 근력부담은 피할 수 없는 실정이다. 따라서 거동이 불편한 고령자를 태운 주행보조기기를 실내에서 원 활하게 이동시키기 위해서는 수발자의 근력부담을 경감시켜 줄 수 있는 주행보조 시스템의 개발이 필요하다. 하지만, 실 내 이동행위에 있어서 주행보조 시스템의 성능이 수발자의 근력에 미치는 영향을 체계적으로 연구한 예는 보고된 적이 없다.

본 연구에서는 여성 수발자를 대상으로 주행보조시스템 이 장착된 샤워캐리어의 주행성 시험(Drivability Test)을 수행하여, 주행보조 시스템의 이동속도에 따른 수발자의 상 체근육의 근활성도에 미치는 영향을 고찰하였다.

\section{Method}

\subsection{Drivability tests}

\subsubsection{Development of test equipment}

저자들이 요양시설에서 확인한 결과, 샤워캐리어를 이용한 실내이동은 주로 2 인의 여성 수발자에 의하여 진행되며, 고 령자의 머리 방향을 전방으로 향하게 하여 이동하게 된다. 한편, 조향은 전방의 수발자가 담당하므로 주행보조 기능은 전방 배치가 필요하며, 후방의 수발자는 이동을 담당하게 된 다(Figure 2). 이러한 실내이동 조건을 고려하여 본 연구에 서는 주행성 시험을 위하여 샤워캐리어 본체와 주행보조 시 스템의 시제품을 신규로 제작하여 시험장비를 구성하였다.

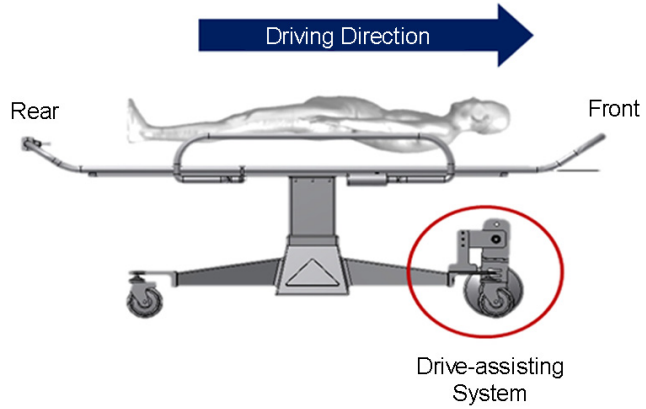

Figure 2. Design concept of drive-assisting system installed in shower carrier

샤워캐리어 본체의 경우에는 고령자가 탐승하는 Bed 부, Dual Actuator 내장의 3단 Column 구조의 Lifting Module 부, 전도 안전성이 확보된 일체형 Base 부로 구성되었다 (Figure 3). 한편, 주행보조 시스템에 대해서는 고령자가 탑 승한 샤워캐리어의 실내이동을 고려하여, 초기 설계기준을 
최대하중 $300 \mathrm{~kg}$, 주행속도 $1 \mathrm{~m} / \mathrm{s}$, 가속시간 $1 \mathrm{sec}$ 로 설정 하여 Motor 용량(350W)과 주행보조 Wheel Size(외경 $\varnothing 210 \mathrm{~mm}$ )를 선정하였다(Figure 4).

또한 제어기(Controller)를 통하여 인가전압에 따라 속 도 조절이 가능한 내장형 Hub Motor(8FUN DX, ECOI)에 Silicon 재질의 Ring을 Molding하여 일체형으로 제작하였고, 좌우 Bracket에 의하여 주행보조 시스템을 샤워캐리어의 Base Frame에 고정하였다(Figure 5).

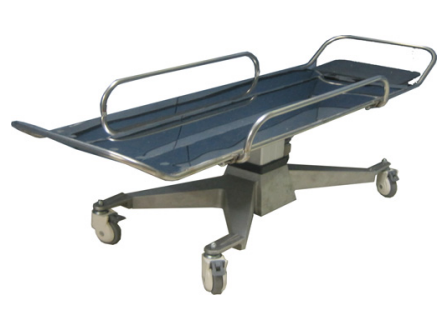

\begin{tabular}{|c|c|}
\hline Bed Length $(\mathrm{mm})$ & 1,900 \\
\hline Bed Width $(\mathrm{mm})$ & 650 \\
\hline Bed Height $(\mathrm{mm})$ & $600 \sim 1,100$ \\
\hline Stroke(mm) & 500 \\
\hline Wheel Size & $\varnothing 125$ \\
\hline Weight & $65 \mathrm{~kg}$ \\
\hline
\end{tabular}

Figure 3. Newly developed shower carrier prototype

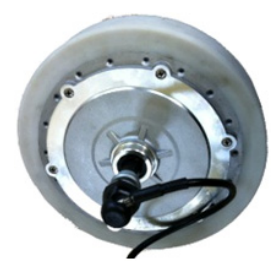

\begin{tabular}{|c|c|}
\hline Model & 8FUN DX \\
\hline Motor Capacity (W) & 350 \\
\hline Diameter(mm) & $\varnothing 210$ \\
\hline Width(mm) & 60 \\
\hline Weight(kg) & 3 \\
\hline
\end{tabular}

Figure 4. Specification of drive-assisting system prototype

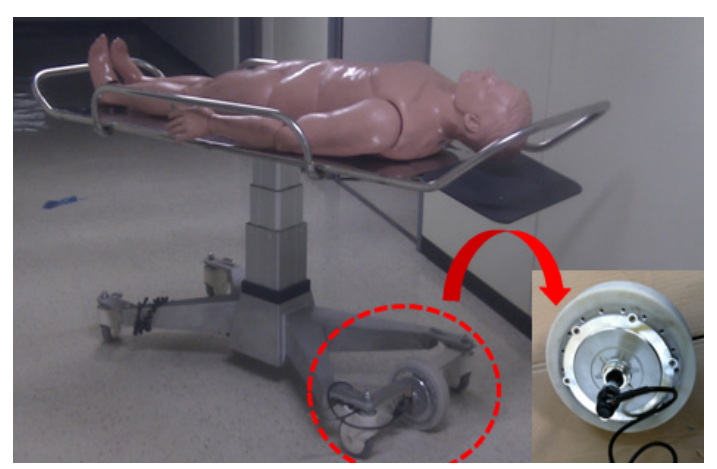

Figure 5. Shower carrier prototype equipped with drive-assisting system

\subsubsection{Selection of subjects and upper body muscles}

주행보조 시스템이 구비된 샤워캐리어의 주행성 시험을 위하여 40대 여성 6인(연령: $43 \pm 4$ 세, 신장: $157 \pm 5 \mathrm{~cm}$, 팔
꿈치 높이: $100.5 \pm 3.5 \mathrm{~cm}$, 어깨너비: $38.3 \pm 2.3 \mathrm{~cm}$, 체중: $54.5 \pm 1.5 \mathrm{~kg}$ ) 을 피험자로 선정하였다. 피험자의 근활성도를 측정하기 위하여 상반신 7개소 근육(승모근: TM/Trapezius Muscle, 삼각근: DM/Deltoid Muscle, 위팔두갈래근: $\mathrm{BBM} /$ Biceps Brachii Muscle, 위팔세갈래근: TBM/Triceps Brachii Muscle, 긴노쪽손목폄근: ECRLM/Extensor Carpi Radialis Longus Muscle, 자쪽손목굽힘근: FCUM/Flexor Carpi Ulnaris Muscle, 척주기립근: ESM/Erector Spinae Muscle)을 선정하였다(Figure 6). 이 가운데서 위팔두갈래 근 $(\mathrm{BBM})$, 위팔세갈래근 $(\mathrm{TBM})$, 긴노쪽손목폄근(ECRLM), 자쪽손목굽힘근(FCUM)은 상지근(UL/Upper Limb: BBM+ $\mathrm{TBM}+\mathrm{ECRLM}+\mathrm{FCUM}$ ) 으로 그룹화하여 분석하였다.

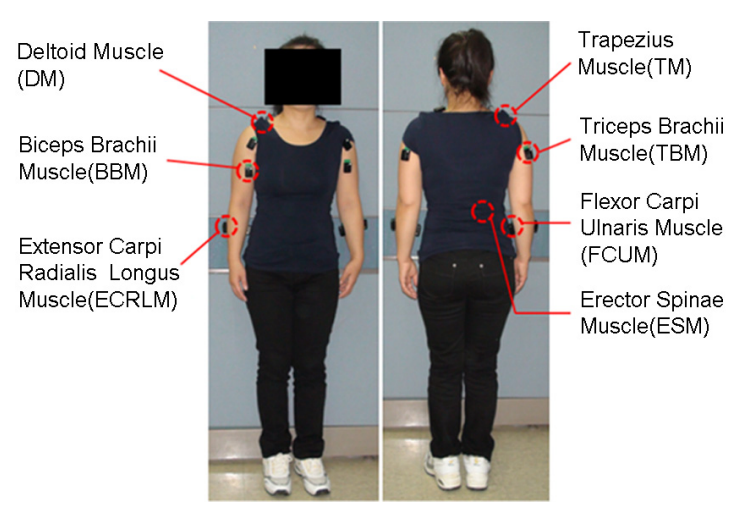

Figure 6. EMG sensors attached to female subjects in their 40s

일반적으로, $\mathrm{EMG}$ 는 운동 중 근육의 전기적 활동을 측정 하는 것으로 스포츠 의학, 인간공학, 전문 임상실험 등의 연 구분야에 효과적으로 사용된다(Hur et al., 2011 / Kim et al., 2011). 본 연구에서는 무선 근전도 측정장비 (Trino ${ }^{\mathrm{TM}} \mathrm{Lab}$ Wireless System, Delsys Inc, USA)를 이용하여 측정하였 으며, 측정된 데이터는 근전도 분석프로그램 (MyoResearch $\mathrm{XP}$, Noraxon Inc, USA)을 사용하여 정류화(Rectification)-RMS 평활화(Smoothing) - 정규화(Normalization) -Bandpass Filter $(10 \sim 350 \mathrm{~Hz})$ 신호처리 과정을 거쳐 근 활성화 정도를 정량적으로 분석하였다. 또한 3-5 펄스의 ECG Reduction 기능을 통해 심전도의 영향을 제거하였다.

\subsubsection{Test conditions}

본 연구에서는 경사면 $10^{\circ}$ 의 직진주행 조건으로 주행성 시험을 실시하였다(Figure 7). 또한, 초기 설계기준 주행속 도의 $0 \%(0.00 \mathrm{~m} / \mathrm{s}),, 25 \%(0.25 \mathrm{~m} / \mathrm{s}), 50 \%(0.5 \mathrm{~m} / \mathrm{s}), 75 \%$ $(0.75 \mathrm{~m} / \mathrm{s})$ 의 조건으로 주행성 시험을 수행하기 위하여, Hub Motor의 인가전압을 각각 $0.0 \mathrm{~V}, 2.0 \mathrm{~V}, 2.1 \mathrm{~V}, 2.3 \mathrm{~V}$ 로 
설정하였다.

한편, 요양기관에서 샤워캐리어를 사용하는 수발자의 행동 패턴에 기초하여, 주행성 시험 시의 샤워캐리어 Gripping 조 건을 수발자의 팔꿈치 높이로 선정하였다. 또한 고령자 탑승 을 고려하여 Bed 부에 60kg 인체 Dummy를 탑재하였다 (Figure 8). 시험횟수는 인가전압(4 Types) 별 8회로 피험 자 당 총 32 회를 실시하였고, 최대/최소를 제외한 6 회의 측 정결과를 사용하였다.

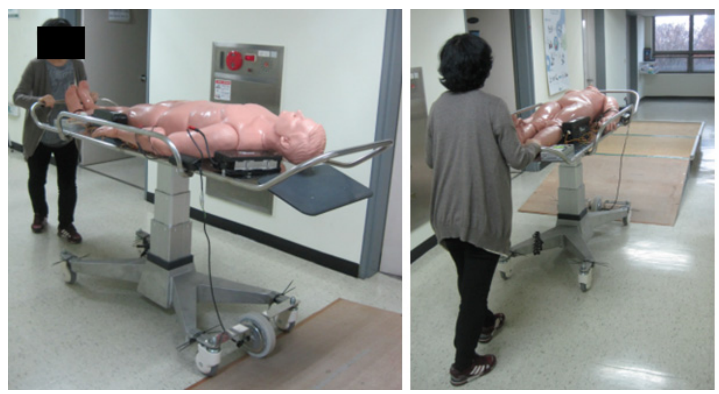

Figure 7. Measurement of muscle activities on the $10^{\circ}$ sloped track
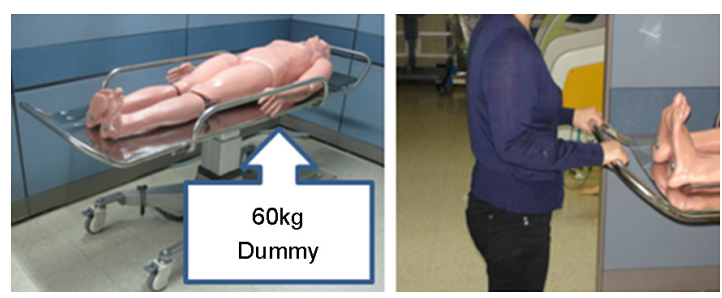

Figure 8. Drivability test conditions of drive-assisting system installed in shower carrier prototype

\subsubsection{Data processing}

$\mathrm{EMG}$ 신호는 센서의 부착위치와 피험자의 신체적 컨디션 등에 따라 영향을 크게 받으므로, 측정결과의 객관적인 비교 /분석을 위하여 정규화(Normalization)가 필요하다.

정규화된 $\mathrm{EMG}$ 신호는 근활성도 분석에 적용 가능하며 통계적 처리에 유용하다. 본 연구에서는 근육 별 측정 자세 (SEED Technology, http://www.seedtech.co.kr)에 근 거하여 실험 전 각 근육에 대해 MMT(Manual Muscle Testing) 방법을 통해 최대 자발적 수축(MVC: Maximum Voluntary Contraction)을 측정하였으며(Figure 9), 측정된 $\mathrm{MVC} \mathrm{EMG}$ 신호를 이용하여 측정된 근전도를 각각 표준화 하였다.

MVC 및 EMG Data에 대한 신호 처리(Signal Processing)
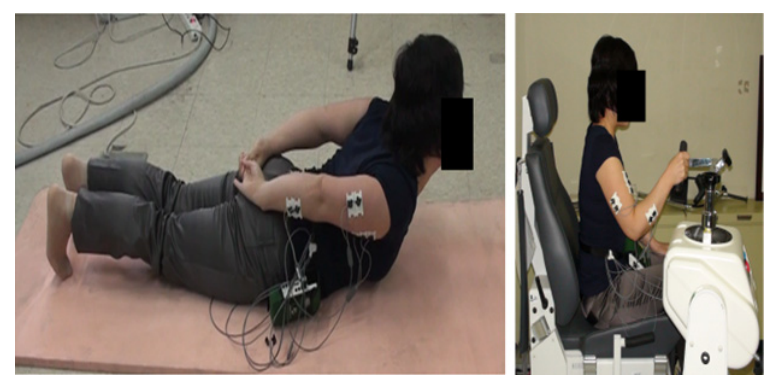

Figure 9. Examples of MVC measurement

시에는, 근활성도 측정결과에 영향을 줄 수 있는 심전도 (ECG: Electrocardiogram) 신호를 제거한 뒤, Filtering을 통하여 $10 \sim 350 \mathrm{~Hz}$ 이외의 Noise를 제거하였다. 이후, 진폭 의 평균, 최대값, 면적의 값을 산출하기 위하여 평활화 기법 (RMS: Root Mean Square)을 사용하였다. 주행속도 간 상 체근육의 근활성도 차이를 보기 위하여 주행속도를 독립변 수로, 상체근육의 근활성도를 종속변수로 하는 일원배치 변 량분석(ANOVA)를 수행하였다. 측정결과에 대한 통계처리 를 위하여 소프트웨어(SPSS 12.0, USA)를 이용하였으며, 통계학적 유의 수준은 0.05로 설정하였다.

\section{Results and Discussions}

주행성 시험결과(Table 1), 승모근(TM)에서의 근활성도 는 37.56 $\pm 9.58 \%(0.0 \mathrm{~V}), 29.58 \pm 16.50(2.0 \mathrm{~V}), 16.21 \pm$ $7.13 \%(2.1 \mathrm{~V}), 14.22 \pm 9.56 \%(2.3 \mathrm{~V})$ 로 확인되었고, 삼각 근 $(\mathrm{DM})$ 에서는 $66.59 \pm 13.16 \%(0.0 \mathrm{~V}), 40.16 \pm 14.26 \%$ $(2.0 \mathrm{~V}), 29.24 \pm 7.19 \%(2.1 \mathrm{~V}), 20.53 \pm 7.68(2.3 \mathrm{~V})$ 로 측 정되었다. 또한, 상지근(UL)에서는 $16.68 \pm 3.84 \%(0.0 \mathrm{~V})$, $13.78 \pm 5.14 \%$ (2.0V), 8.76 $\pm 2.55 \%(2.1 \mathrm{~V}), 7.95 \pm 3.34$ $(2.3 \mathrm{~V})$ 로 확인되었고, 척주기립근(ESM)에서는 $21.40 \pm$ $11.71 \%$ (0.0V), $17.22 \pm 10.94 \%$ (2.0V), $14.13 \pm 6.83 \%$ $(2.1 \mathrm{~V}), 12.36 \pm 5.74(2.3 \mathrm{~V})$ 로 측정되었다. 여기서, $\mathrm{Hub}$ Motor의 인가전압에 따른 근활성도에 대해서는 통계적으로 유의적인 차이가 확인되었다 $(p<0.05)$.

각 근육에 있어서 근활성도의 변화율(Rate of Change)를 살펴보면 다음과 같다. 먼저, 승모근(TM)에서는, $0.0 \mathrm{~V}$ 대 비 $2.0 \mathrm{~V}$ 의 경우 $-21 \%, 2.1 \mathrm{~V}$ 의 경우 $-57 \%, 2.3 \mathrm{~V}$ 경우에 는 $-62 \%$ 의 결과가 얻어졌고, 삼각근 $(\mathrm{DM})$ 에서는, $0.0 \mathrm{~V}$ 대비 $2.0 \mathrm{~V}$ 경우 $-40 \%, 2.1 \mathrm{~V}$ 경우 $-56 \%, 2.3 \mathrm{~V}$ 경우에는 $-69 \%$ 가 확인되었다 $(p<0.05)$. 또한 상지근 $(\mathrm{UL})$ 에서는, $0.0 \mathrm{~V}$ 대비 $2.0 \mathrm{~V}$ 의 경우 $-17 \%, 2.1 \mathrm{~V}$ 의 경우 $-47 \%, 2.3 \mathrm{~V}$ 
Table 1. Summary of muscle activities from drivability tests of shower carrier with drive-assisting system

\begin{tabular}{|c|c|c|c|c|c|c|c|c|c|c|c|c|}
\hline \multirow{2}{*}{$\begin{array}{l}\text { Voltage } \\
\text { (V) }\end{array}$} & \multicolumn{3}{|c|}{ TM } & \multicolumn{3}{|c|}{ DM } & \multicolumn{3}{|c|}{ UL } & \multicolumn{3}{|c|}{ ESM } \\
\hline & AVG.(\%) & S.D. & Rate(\%) & AVG.(\%) & S.D. & Rate $(\%)$ & AVG.(\%) & S.D. & Rate $(\%)$ & AVG.(\%) & S.D. & Rate(\%) \\
\hline 0.0 & 37.56 & 9.58 & $*$ & 66.59 & 13.16 & $*$ & 16.68 & 3.84 & $*$ & 21.40 & 11.71 & $*$ \\
\hline 2.0 & 29.58 & 16.50 & -21 & 40.16 & 14.26 & -40 & 13.78 & 5.14 & -17 & 17.22 & 10.94 & -20 \\
\hline 2.1 & 16.21 & 7.13 & -57 & 29.24 & 7.19 & -56 & 8.76 & 2.55 & -47 & 14.13 & 6.83 & -34 \\
\hline 2.3 & 14.22 & 9.56 & -62 & 20.53 & 7.68 & -69 & 7.95 & 3.34 & -52 & 12.36 & 5.74 & -42 \\
\hline
\end{tabular}

경우에는 $-52 \%$ 가 얻어졌고 $(p<0.05)$, 척주기립근 $(\mathrm{ESM})$ 에 서는 $0.0 \mathrm{~V}$ 대비 $2.0 \mathrm{~V}$ 의 경우 $-20 \%, 2.1 \mathrm{~V}$ 의 경우 $-34 \%$, $2.3 \mathrm{~V}$ 경우에는 $-42 \%$ 가 확인되었다 $(p<0.05)$. 이러한 결 과로부터, Hub Motor의 인가전압에 따른 피험자의 상반신 근육의 근활성도는 삼각근 $(\mathrm{DM})$, 승모근 $(\mathrm{TM})$, 척주기립근 $(\mathrm{ESM})$, 상지근(UL)의 순서로 감소하는 경향이 확인되었다 (Figure 10).

상기의 결과를 고찰하면, Hub Motor의 인가전압이 높을수 록 선정된 근육에서의 근활성도는 기존의 수동식 이동보조 기기에 비해 근육 별로 최소 $42 \%$, 최대 $62 \%$ 정도 감소하 는 결과가 얻어짐으로, 주행보조 시스템을 이용한 샤워캐리 어의 실내이동 시 수발자의 근력부담은 크게 경감될 것으로 추론된다. 따라서 향후 수발자의 근력부담을 줄여주기 위해 서는 주행보조 시스템이 구비된 샤워캐리어의 개발이 무엇 보다 필요한 것으로 판단된다.

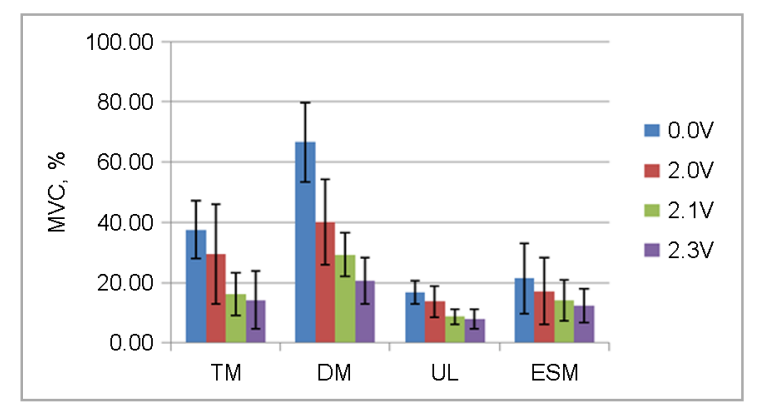

Figure 10. Comparison of muscle activities from drivability tests of shower carrier with drive-assisting system

\section{Conclusion}

본 연구에서는 40대 여성 피험자를 대상으로 주행보조 시 스템이 구비된 샤워캐리어의 주행성 시험을 수행하였고, 이
를 토대로 주행보조 시스템의 주행속도에 따른 수발자의 상 체근육의 근활성도에 미치는 영향을 고찰해 보았다.

주행성 시험을 위하여 샤워캐리어 본체와 주행보조 시스 템의 시제품을 제작하였고, 초기 설계기준 주행속도의 $0 \%$ $(0.00 \mathrm{~m} / \mathrm{s}), 25 \%(0.25 \mathrm{~m} / \mathrm{s}), 50 \%(0.5 \mathrm{~m} / \mathrm{s}), 75 \%(0.75 \mathrm{~m} / \mathrm{s})$ 의 조건에 해당되는 Hub Motor의 인가전압 $(0.0 \mathrm{~V}, 2.0 \mathrm{~V}$, $2.1 \mathrm{~V}, 2.3 \mathrm{~V})$ 을 설정하여 경사면에서의 피험자의 근활성도를 측정하였다.

Hub Motor의 인가전압이 높을수록 피험자의 상반신 근육 에 있어서의 근활성도는 크게 감소하는 결과가 얻어져, 수발 자의 근력부담이 크게 경감 가능할 것으로 추론되었다.

향후, 본 연구결과를 이용하여 수발자의 근력부담 경감이 기대되는 주행보조 시스템이 구비된 샤워캐리어 개발이 가 능할 것으로 판단되며, 고령자 개호활동에 필요한 다양한 이 동 보조장비의 개발에도 유용하게 활용될 수 있을 것으로 기대된다.

\section{Acknowledgements}

This study was performed with assistance from the research fund of the Ministry of Health and Welfare in Korea(A101945).

\section{References}

Cho, et al., "Development of a Shower Carrier based on the Needs in Long-term Care Institutions.", Journal of the Ergonomics Society of Korea, 31(2), 379-388, 2012.

Hur, et al. "Difference of Lumbar \& Lower Extremity Muscle Activity when Patients are Transferred by Physical Therapists.", Journal of the Ergonomics Society of Korea, 30(5), 613-619, 2011.

iSTANDARD, http://www.istandard.or.kr

Kim, et al., "Effets on the Lumbar \& Quadriceps Muscle Activity When Patients are Transferred by Physical Therapists.", Journal of the 
Ergonomics Society of Korea, 30(5), 613-619, 2011.

National Statistical Office, 2010 Social Indicators in Korea, 2011.

SEED Technology Homepage, http://www.seedtech.co.kr

The Korean Gerontological Society, Understanding of Gerontology,

Daeyoung Munhwa Publishing Co., pp. 142-143, 2002

\section{Author listings}

\section{Cheol Woong Ko: cheko@kitech.re.kr}

Highest degree: Ph.D. Department of Mechanical and Environmental Informatics, Tokyo Institute of Technology

Position title: Director/Principal Researcher, Smart Welfare Technology R\&D Group, Korea Institute of Industrial Technology (KITECH)

Areas of interest: Human Finite Element Modeling, Computational Simulation, Biomechanics, Biomedical Engineering, Rehabilitation Engineering
Deok Yeon Cho: deokyeon@swa.co.kr

Highest degree: Master, Nano-IT Fusion Program, Seoul National University of Science and Technology

Position title: Assistant Research Engineer, Hyundai Sungwoo

Automotive Korea Co., Ltd.

Areas of interest: Mechanical Design

Tae Soo Bae: bmebae@jwu.ac.kr

Highest degree: $\mathrm{Ph} . \mathrm{D}$. Department of Mechanical Engineering, Korea University

Position title: Assistant Professor, Department of Biomedical Engineering, Jungwon University

Areas of interest: Musculoskeletal Model, Dynamic Analysis,

Rehabilitation Engineering, Motion Analysis

Date Received : 2012-08-14

Date Revised :2013-08-09

Date Accepted : 2013-08-23 